\title{
Transfer of European Clock-Making Technology into China during the Seventeenth and Eighteenth Centuries
}

\section{ZHANG Baichun 张柏春 ${ }^{1}$}

(Institute for the History of Natural Sciences, Chinese Academy of Sciences, Beijing 100190, China)

\begin{abstract}
From the 1580s onwards, Catholic missionaries introduced European mechanical clocks into China as gifts for officials or emperors, with the aim of establishing a good relationship with the Chinese leadership in order to do missionary work. After the seventeenth century, European clock-makers in the imperial palace made complicated clocks according to the emperors' desires. There were a number of workshops for producing European-style clocks in Guangzhou, Suzhou, Nanjing, and other cities during the eighteenth and nineteenth centuries. It was, however, difficult for the experienced craftsmen to innovate new clockwork. The main reasons for the development of European clock technology in China were its technical superiority, the missionaries' introduction, and the Chinese interest in clocks.
\end{abstract}

Keywords: clock, technology transfer, China

Furope's expansion into Asia accelerated in the sixteenth century. Macao became the missionaries could settle. In the early 1580s the missionaries acquired the assistance of Chinese officials and began to live and preach in China. They gradually extended their mission to different provinces and even into the imperial court in Beijing. The strategy they adopted was to spread European science and technology based on adapting to Chinese culture, which created conditions for the spread of Catholicism. In the late Ming dynasty and the early Qing dynasty, emperors were wary of the missionaries' religious activities, but welcomed their scientific and technical talents for the benefit of the court (Zhang et al. 2008, 291-292). It was in this context that European clocks and watches were imported into China by missionaries and traders, and imitated by the imperial and private workshops. This is the so-called transfer of clock-making technology from Europe to China.

Received: April 9, 2020. Revised: November 30, 2020.

1 Research interest: History of science and technology. Email: zhang-office@ihns.ac.cn 


\section{Introduction of European clocks into China}

In pre-modern China there were timepieces such as the sundial, clepsydra, sandglass, and water-driven clock (Figures 1 and 2). The sundial was convenient to use, but it was not suitable for cloudy days and the nighttime. Because of its large size the clepsydra could not be moved easily, nor could it be used normally in cold conditions. The multitank clepsydra was high in precision, but was mainly applied in astronomical observatories. The sandglass operated with the same principle as the clepsydra, and the only difference was that the water was replaced by sand. The water-driven clock of the eighth to eleventh century was a large astronomic device of the imperial court, which took advantage of water wheels to drive the timing device and celestial globe, and

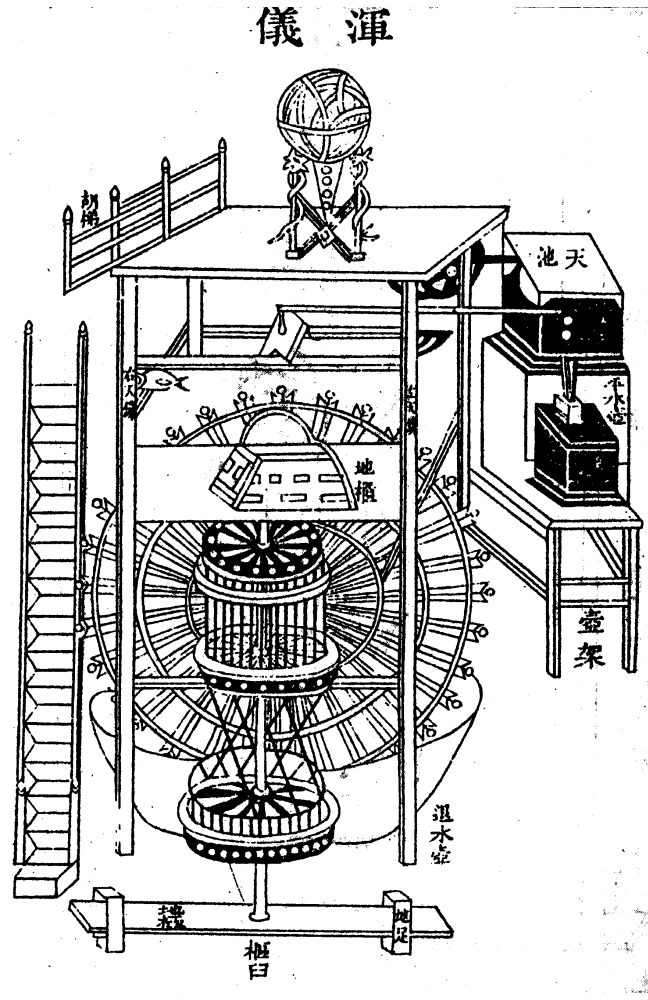

Figure 1

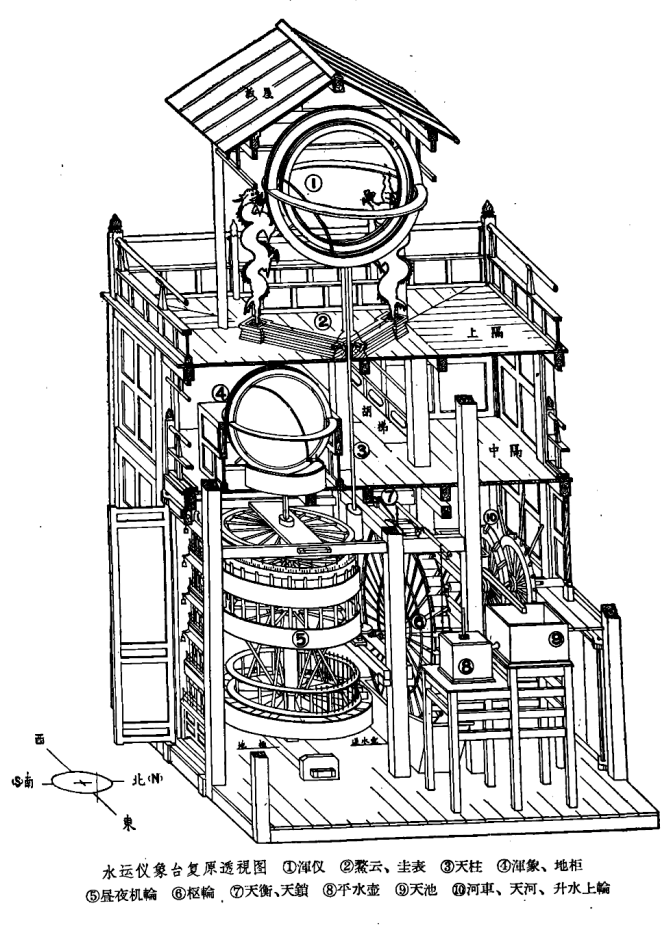

Figure 2

Figure 1: Internal structure of the astronomical clock-tower constructed by Su Song 蘇頌 and Han Gonglian 韓公廉 in 1092 (Su 1994, 315).

Figure 2: Wang Zhenduo's 王振铎 reconstruction of the astronomical clock-tower includes (1) armillary sphere, (2) pedestal and gnomon, (3) main vertical transmission-shaft, (4) celestial globe, (5) day and night time-keeping wheels, (6) driving wheel, (7) upper balancing lever and upper lock of the escapement, (8) constant-level tank, (9) upper water reservoir, and (10) norias and manual wheel for operating them (Wang 1958). 
therefore was not suitable for everyday timekeeping (Needham 1965, 446-515). Since the twelfth century, the water-driven clock had no longer been constructed in China. In comparison, European mechanical clocks and watches were made of metal, and could vary in size as well as being compact and durable in structure. They were more accurate in timekeeping, exquisite in design, and could even be accompanied by ingenious demonstrations. These superiorities made European clocks and watches both practical timepieces and artistic furnishings for display or appreciation. Then the missionaries noticed that the timepieces in China were not as perfect as those in Europe.

When European clocks were introduced they were warmly welcomed by the Chinese and had become a tool for missionaries to get closer to Chinese officials. In 1579 the Italian Jesuit Michele Ruggieri arrived at Macao. In the spring of 1581 he visited Guangzhou and won the favor of a Chinese military officer with the gift of a mechanical clock (Bernard 1936, 190). Then in December of 1582, Ruggieri and another Jesuit went to Zhaoqing in a hurry, taking with them prisms and a large mechanical clock as gifts. They finally pleased Chen Rui 陳瑞, satrap in charge of Guangdong and Guangxi. On September 10, 1583, Ruggieri and Matteo Ricci returned to Zhaoqing with a large number of skillfully made devices from Europe, and the newly appointed satrap Guo Yingpin 郭應聘 agreeably allowed them to build a church. The missionaries therefore discovered the great influence that skillfully made devices and academic achievements from Europe had, such that clocks and prisms were then sent to very important people as gifts whenever the Jesuits wanted to promote their mission in a new area. After some twists and turns, Ricci and his team finally had the chance to visit the Wanli emperor in January 1601. They won the favor of the emperor with two mechanical clocks and other gifts, and obtained authorization to live in Beijing. Ricci's success had consolidated the status of Catholic missionaries in China.

The Qing army took over Beijing in 1644, and thus the Ming dynasty was replaced by the Qing dynasty. The Jesuits turned to the new court to gain the opportunity to continue their mission in China. Because the emperors and their ministers in the Qing dynasty were generally fond of Western gadgets such as clocks, the European missionaries and envoys always selected sophisticated clocks as gifts to present to the emperors. Emperor Kangxi was strongly interested in European science and technology. In 1694 he wrote a poem in praise of the European mechanical clocks: "they are superior to clepsydra, operating day and night, and telling the time accurately" (Fang 1987, 758). ${ }^{2}$ Emperor Yongzheng also praised the clocks without stint: "clocks are of the most excellence among all the European rare treasures" (Aisin Gioro and Ji 1986, 163). ${ }^{3}$

In the reign of Emperor Kangxi (1662-1722), European businessmen began to sell different types of clocks in Guangzhou. Then, clocks became the most important

2 “書夜循環勝刻漏, 綢繆宛轉報時全。”

3 “珍奇爭貢獻, 鐘錶極精工。” 
products imported from Europe to China. Emperor Qianlong was far more interested in clocks than Emperor Kangxi and collected more clocks in the imperial court. In the reign of Emperor Qianlong (1736-1795), China's importation of clocks increased (Figures 3.1 and 3.2), and clocks and watches became necessities for many dignitaries' families. For instance, in 1799, Heshen 和珅, an important dignitary of the Qing dynasty, was found to have 10 large mechanical clocks, over 300 small clocks, and more than 280 European watches at his home (Ju 1989). It was only in 1786 that the imperial court ordered no more clocks and watches should be submitted.

In order to adapt to Chinese culture, and meet the functional and aesthetic needs of users, European missionaries and craftsmen made necessary adjustments to the design of clocks and watches. In January 1583, the Jesuit Ruggieri modified the mechanical clock that was designed to be presented to the satrap Chen Rui, by adding a clock jar and various decorations. In order to conform to Chinese custom, he converted the European twenty-four-hour system into the Chinese twelve-hour system, and replaced Arabic numerals with Chinese characters (Bernard 1936, 208-209). Before 1601, Matteo Ricci decorated a smaller mechanical clock to be presented to the emperor of the Ming dynasty, by marking the time with Chinese characters such as " $\mathrm{Zi}$ " 子, "Chou" 丑, “Yin" 寅, and “Mao" 卯, and carving an elaborate dragon on the vaulted top of the clock. In the reign of Emperor Kangxi the mechanical clocks made in Suzhou adopted the Chinese twelve-hour system.

\section{The imitation of clocks and watches in China}

Soon after European missionaries entered the Chinese mainland they tried to make clocks locally. In 1583, Ruggieri brought a clock-maker from Macao to Zhaoqing. With the assistance of two local Chinese craftsmen, they finally produced a mechanical clock in 1584, which indicated that Chinese craftsmen were able to make clocks under the leadership of foreign craftsmen or by imitating imported products.

In the reign of Emperor Kangxi there was a "Self-Sounding Clocks Unit" specially for the collection of clocks in the imperial court. It was incorporated into the Royal Workshop in 1723 and renamed as the Clock-Constructing Unit in 1732. Sometimes there were more than one hundred craftsmen. Among them, clock-constructing technology mainly depended on European craftsmen, including Gabriel de Magalhães, Francisco-Louis Stadlin, Jacobus Brocardus, Coadjutor Gilles Thébault, and Mathaeus de Ventavon. There were also some Chinese craftsmen who cooperated with European clock-makers, and the most skilled craftsmen were selected and sent by the governor in Guangdong. When constructing clocks, craftsmen used traditional European tools such as small lathes and combined Western technology with Chinese art, so as to construct clocks that appealed to emperors (Figures 4 and 5). They usually needed to make the 


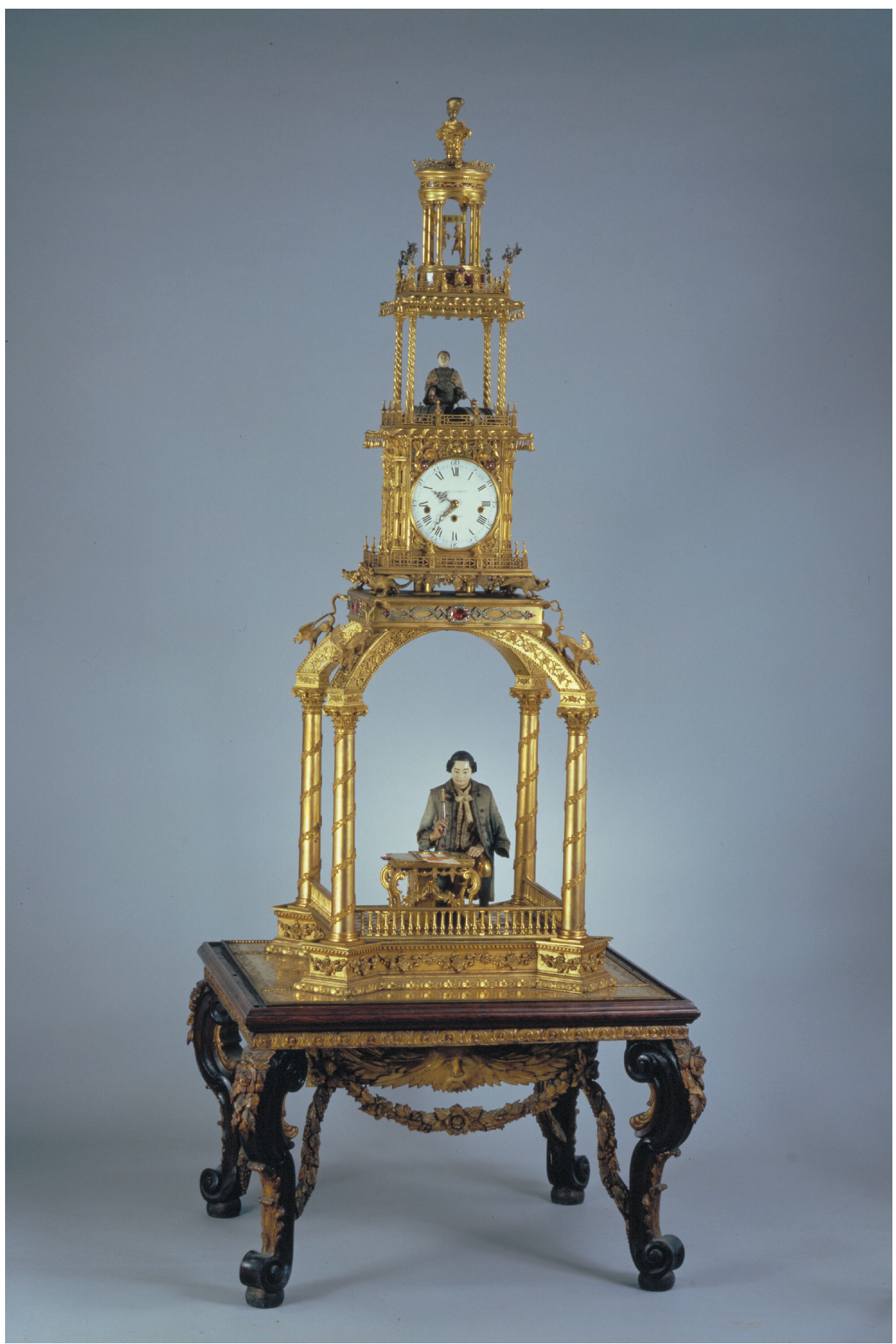

Figure 3.1: Clock with a Western figure writing Chinese characters. Courtesy of the Palace Museum. 


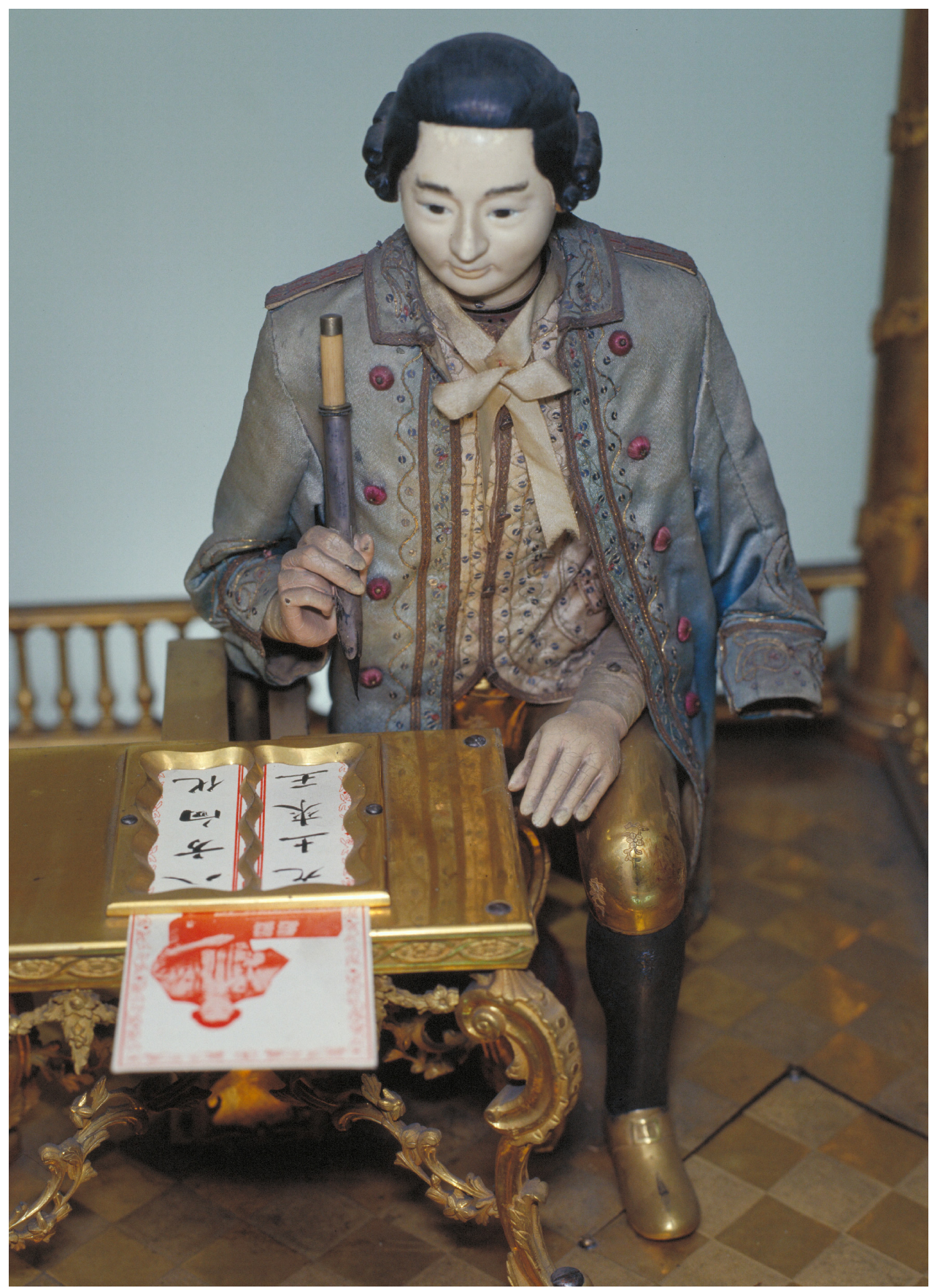

Figure 3.2: Detail of the clock with a Western figure writing Chinese characters. Courtesy of the Palace Museum. 


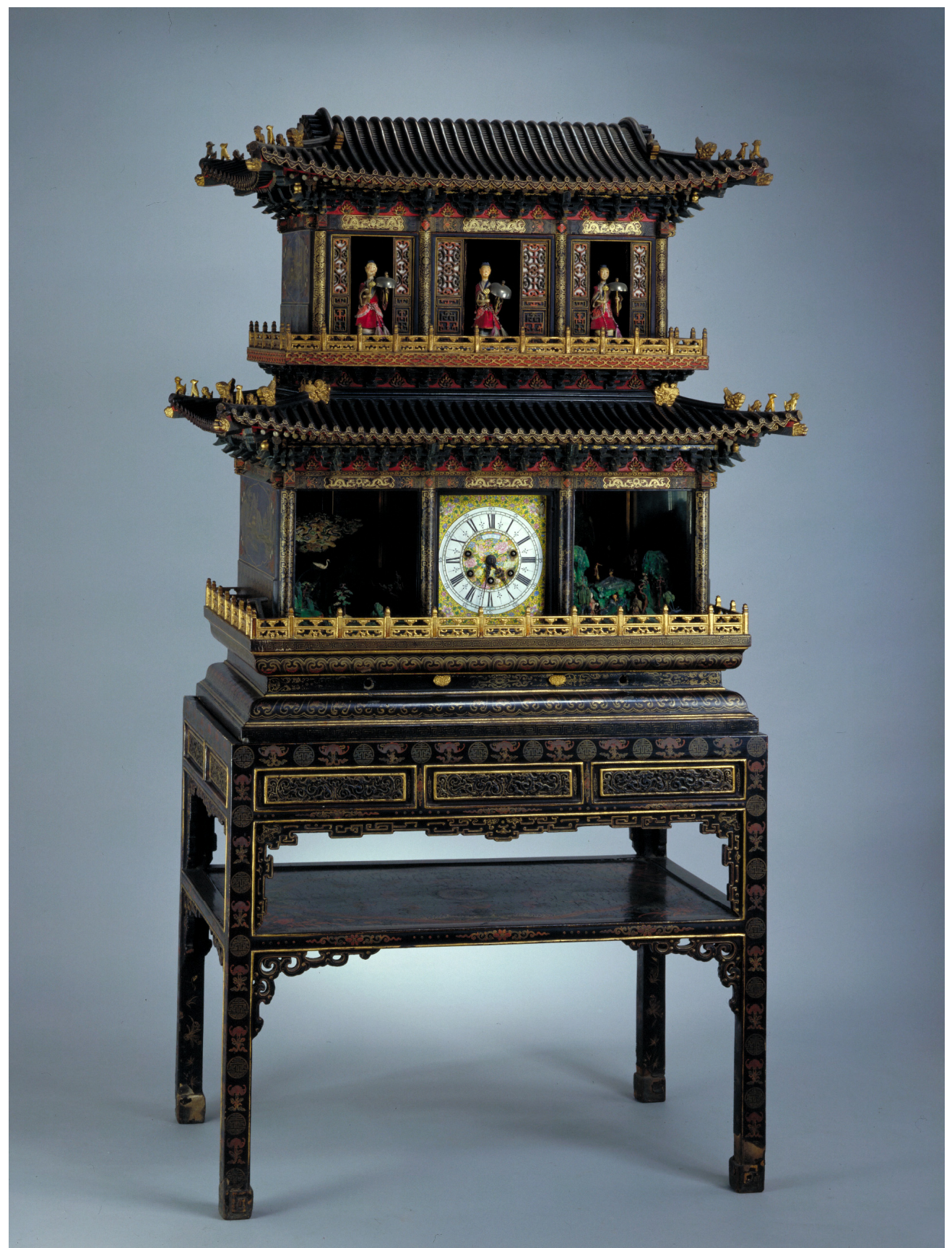

Figure 4: Clock with the decoration of tower, automatic opening doors, and assembled immortals extending wishes for longevity. Courtesy of the Palace Museum. 


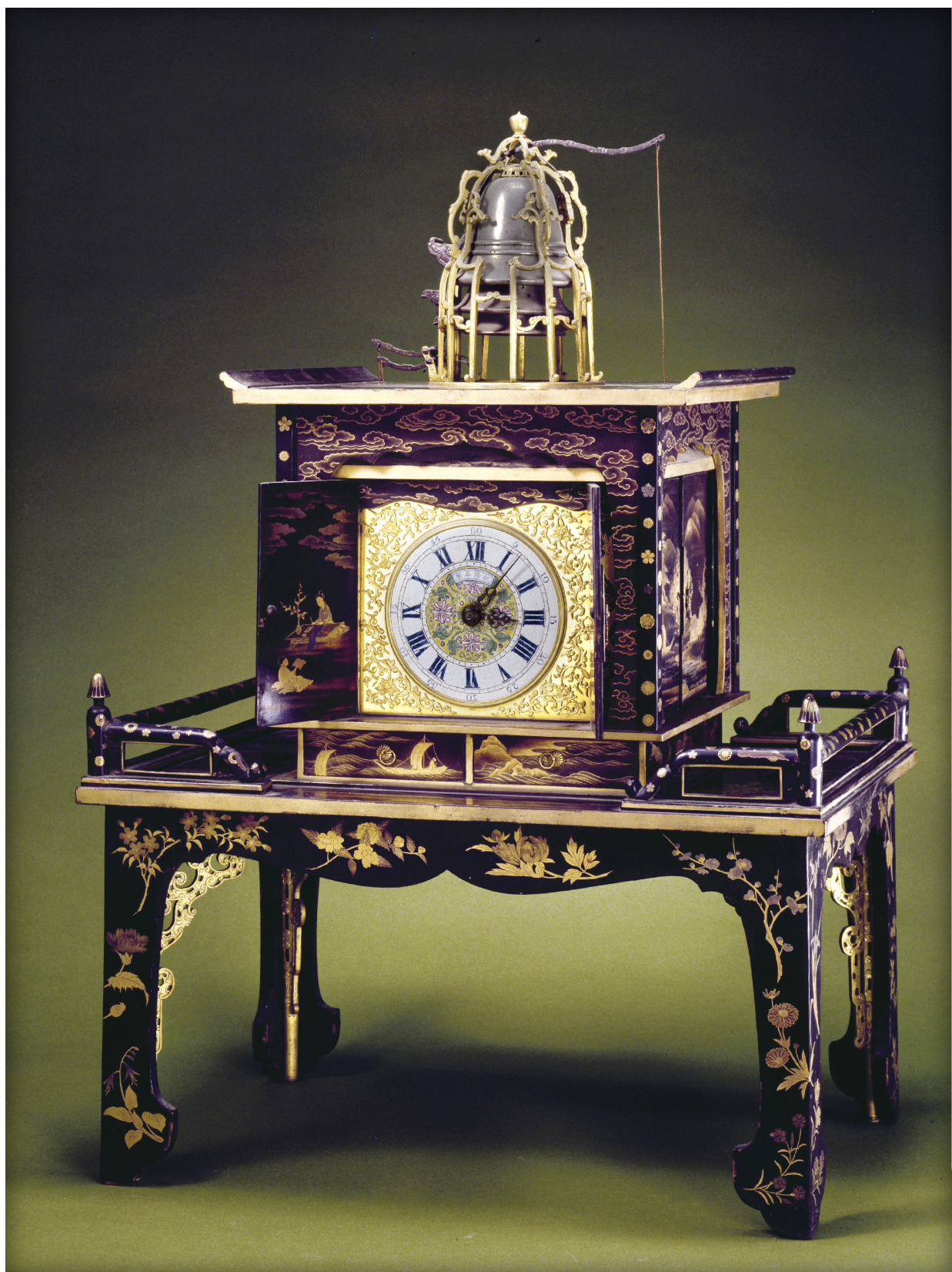

Figure 5: Clock set in black-lacquered tower. Courtesy of the Palace Museum.

clock and its accompanying mechanisms and decorations according to the requirements of emperors in terms of style and function (Figure 6). Throughout the process, emperors could also require changes at any moment. By adopting complicated mechanisms such as mainsprings and gears, craftsmen enabled their clocks to drive 
various delicate contrivances, so as to demonstrate different scenes, such as celestial motion, copper puppets striking a bell, self-walking animals, ducks on water, selfmoving boats, or music playing.

In the early Qing dynasty, the clocks made in the imperial court were mainly weight driven. Subsequently, after the technique of making winding springs had been learned from foreigners, spring-driven clocks were successfully made during the reign of Kangxi (Zhang and Liu 1987, 104). Clock-making in the Clock-Constructing Unit had its heyday in the reign of Emperor Qianlong. Sometimes, European painters or even astronomers would take part in clock-making. It could take a year or two or even longer to complete a clock with complicated functions, therefore the output of the Clock-Constructing Unit was not high. For instance, from 1750 to 1759, the ClockConstructing Unit only produced fifty-six clocks (Liu 1989). All the winding springs used in the Clock-Constructing Unit were bought from Guangzhou and probably imported from Europe. After the reign of Qianlong, clocks were seldom made in the Clock-Constructing Unit. By the late Qing dynasty (before 1911), the unit was in decline and even lost the capability to carry out clock repairs.

In the early seventeenth century, Chinese makers were already trying to imitate European clocks (Chen 1984). For instance, Wang Zheng 王徵, a scholar in Shaanxi, admired the ingenuity of European clocks and succeeded in constructing one by imitation before 1626 (Wang 1830, 12) (Figure 7). In the Qing dynasty (1644-1911), with the constant importation of clocks, early clock workshops came into being in different places, such as Guangzhou, Suzhou, Nanjing, Songjiang, Hangzhou, and Ningbo. ${ }^{4}$ As an import port for clocks, Guangzhou had witnessed the appearance of clock workshops early in the reign of Emperor Qianlong and perhaps even in the reign of Kangxi (Liu 1989). In Suzhou the imitation of mechanical clocks appeared early in the reign of Kangxi, and there were thirty clock-making workshops in total by the middle of the nineteenth century. In Hangzhou and Ningbo, the number of workshops was nine and seven respectively (Chen 1981). Moreover, specialized workshops were established in Suzhou, Nanjing, and Guangzhou to produce devices by the division of labor, including workshops to make clockwork, bells, chains, winding springs, rosewood cases, dials, and engraved flowers. This kind of division of labor was conducive to improved techniques and the production of premium clocks. In the middle and late Qing dynasty, clockworks made in Suzhou were divided into small, medium, and large sizes, and then utilized by many workshops to assemble complete clocks.

The most famous domestic clocks were made in Guangdong and Suzhou. The Guangzhou-made clocks collected by the Palace Museum were usually about one meter

4 Generally, a clock-making workshop consisted of two or three workers. The wife operated a bellows, and the son worked as an apprentice. A craftsman could, perhaps, make one or two clocks each month. 


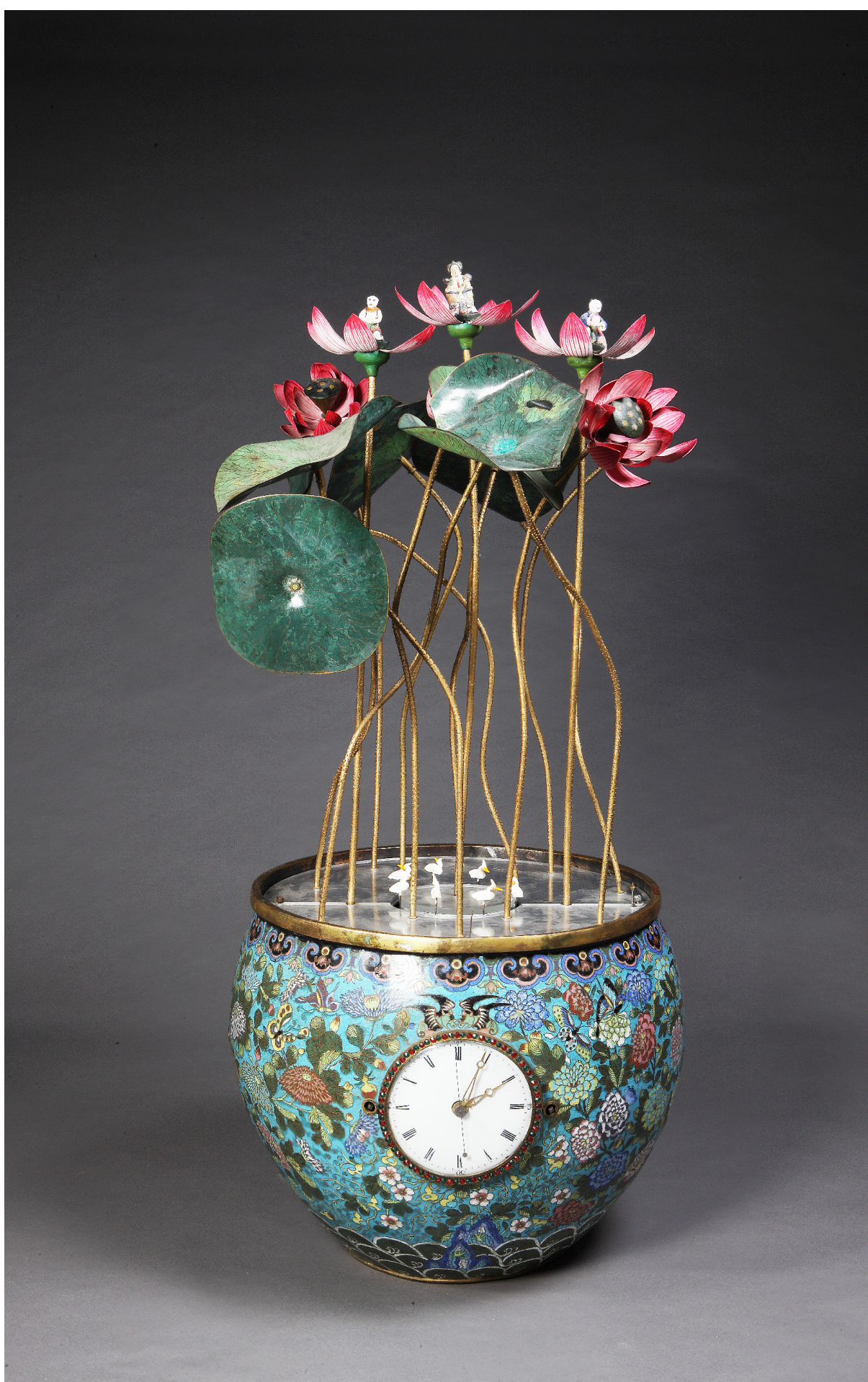

Figure 6: Clock inlaid on a lotus pot. Courtesy of the Palace Museum. 


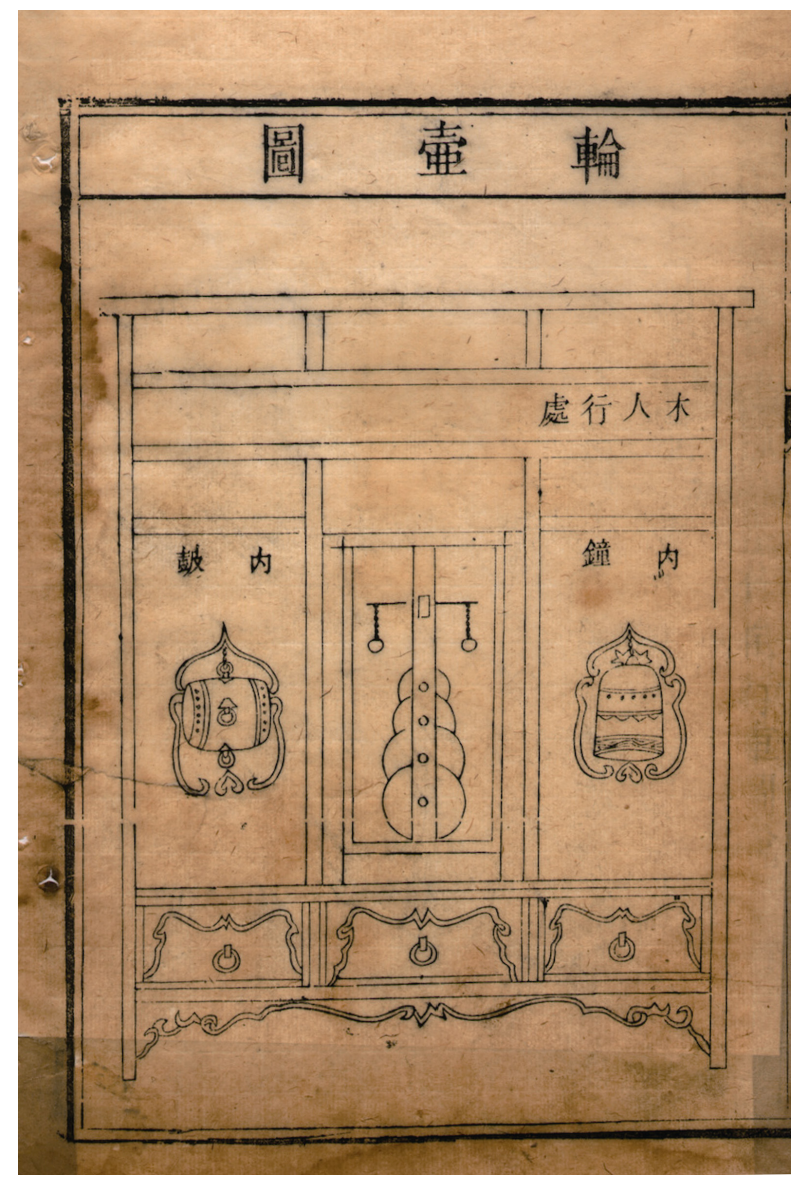

Figure 7: A diagram of Wang Zheng's clock (Wang 1830, 12).

high (Shang 1986). They were mainly modeled to resemble Buddhist towers, gourds (Figure 8), Qilin or other Chinese-style designs, with movable puppets and scenery decorations, such as flowers and streams. Some clocks could even play music. In Suzhou there were also clocks with demonstrative devices and puppets of people and animals. In the late Qing dynasty, the famous clocks from Suzhou were the practical clocks with a case similar to a pre-modern Chinese folding screen. This kind of clock was compact in structure, without any attached devices (Figure 9). Through constant practice, the Chinese finally mastered the mechanical principles and making processes of clocks. In the early nineteenth century, Xu Chaojun 徐朝俊, who was from Songjiang, completed the writing of Illustrations and Descriptions of Self-Sounding Clocks and Watches (Ziming zhongbiao tushuo 自鳴鐘錶圖說). In this book he summarized the craftsmen's practical knowledge and their techniques for making and repairing clocks (Figure 10). 


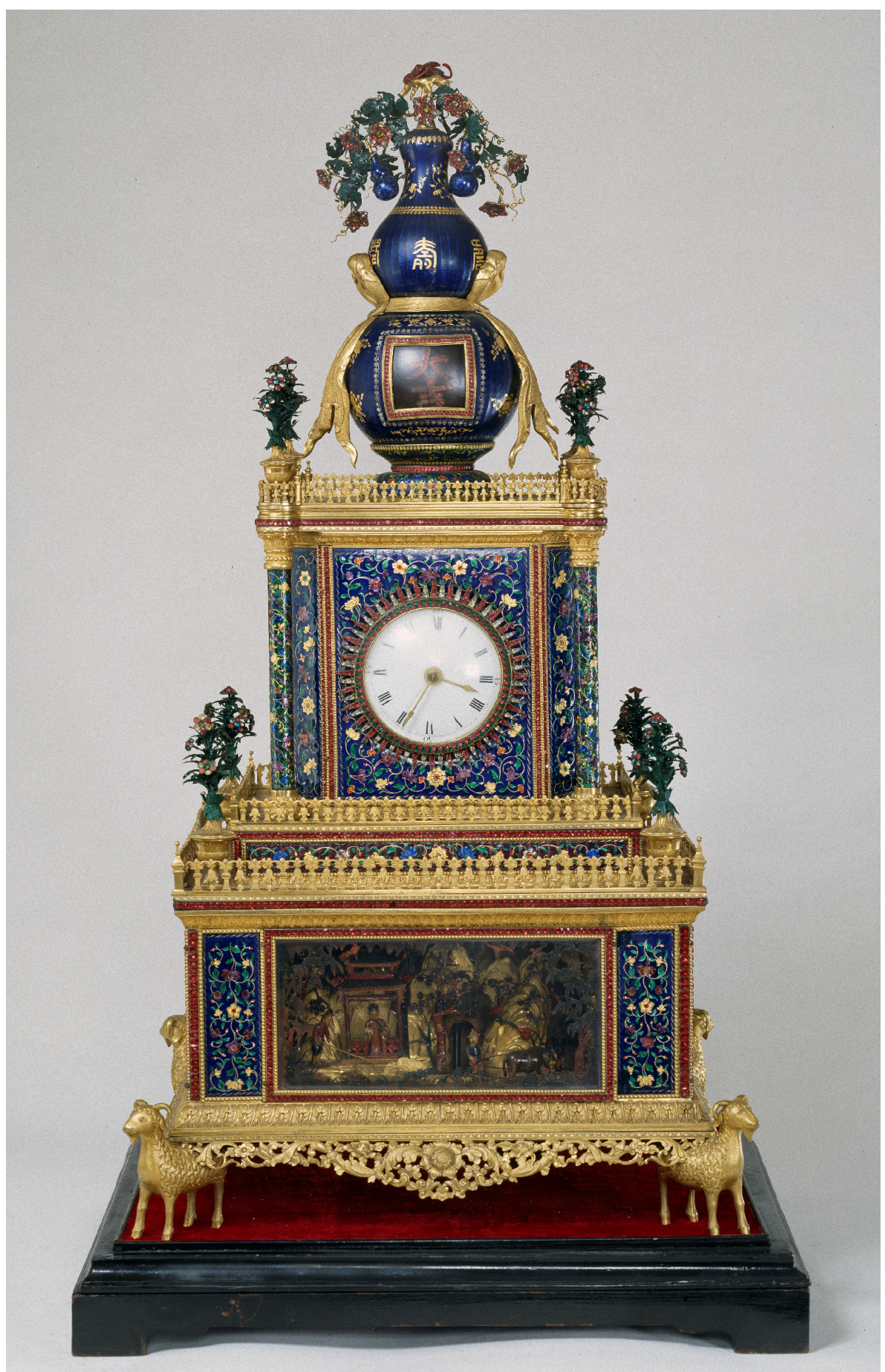

Figure 8: Clock with the decoration of gourd and design of fisherman, woodcutter, farmer, and scholar. Courtesy of the Palace Museum. 


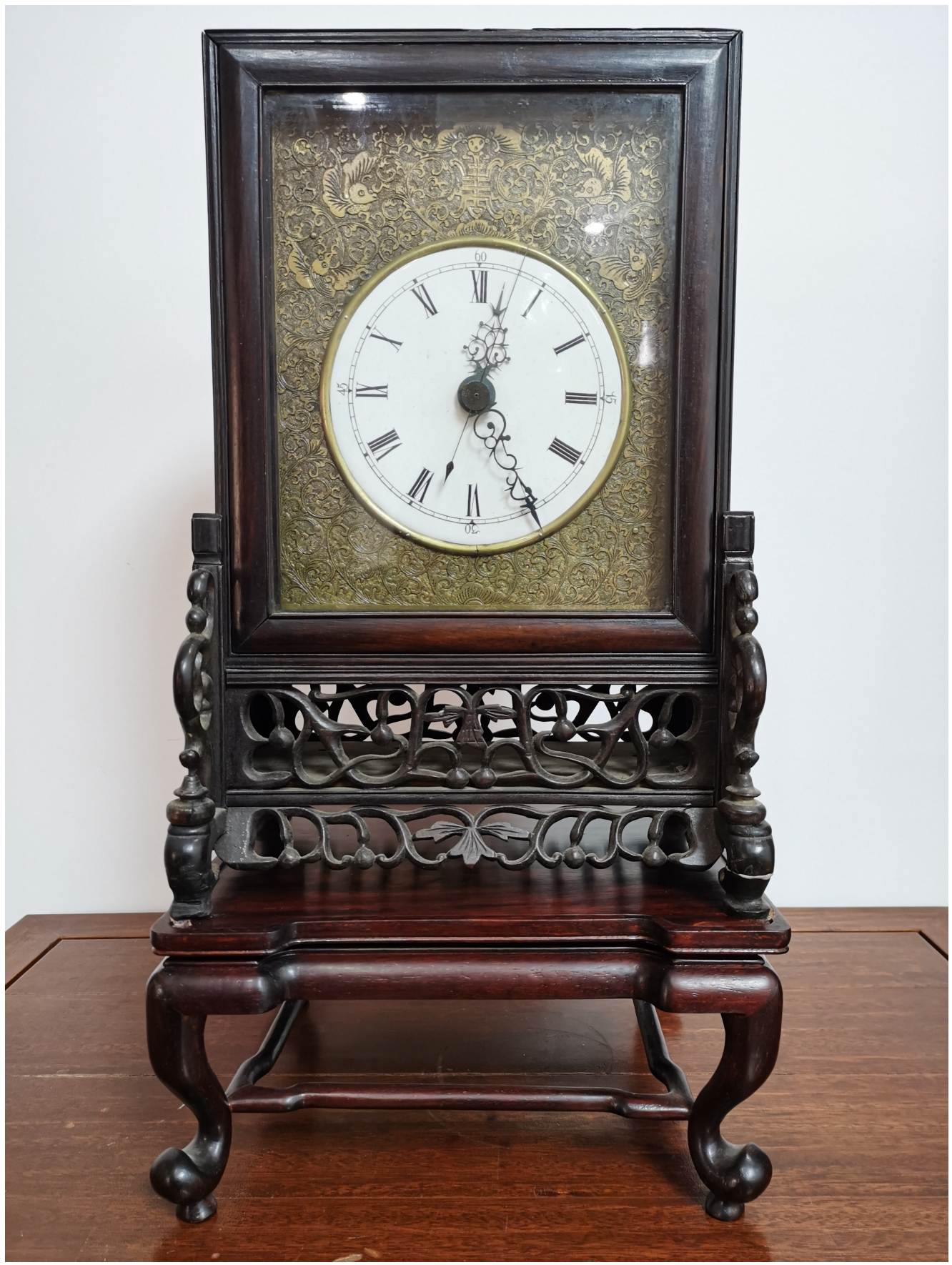

Figure 9: A clock made in Suzhou in the nineteenth century. Photo by Chen Shigang 陈士刚. 


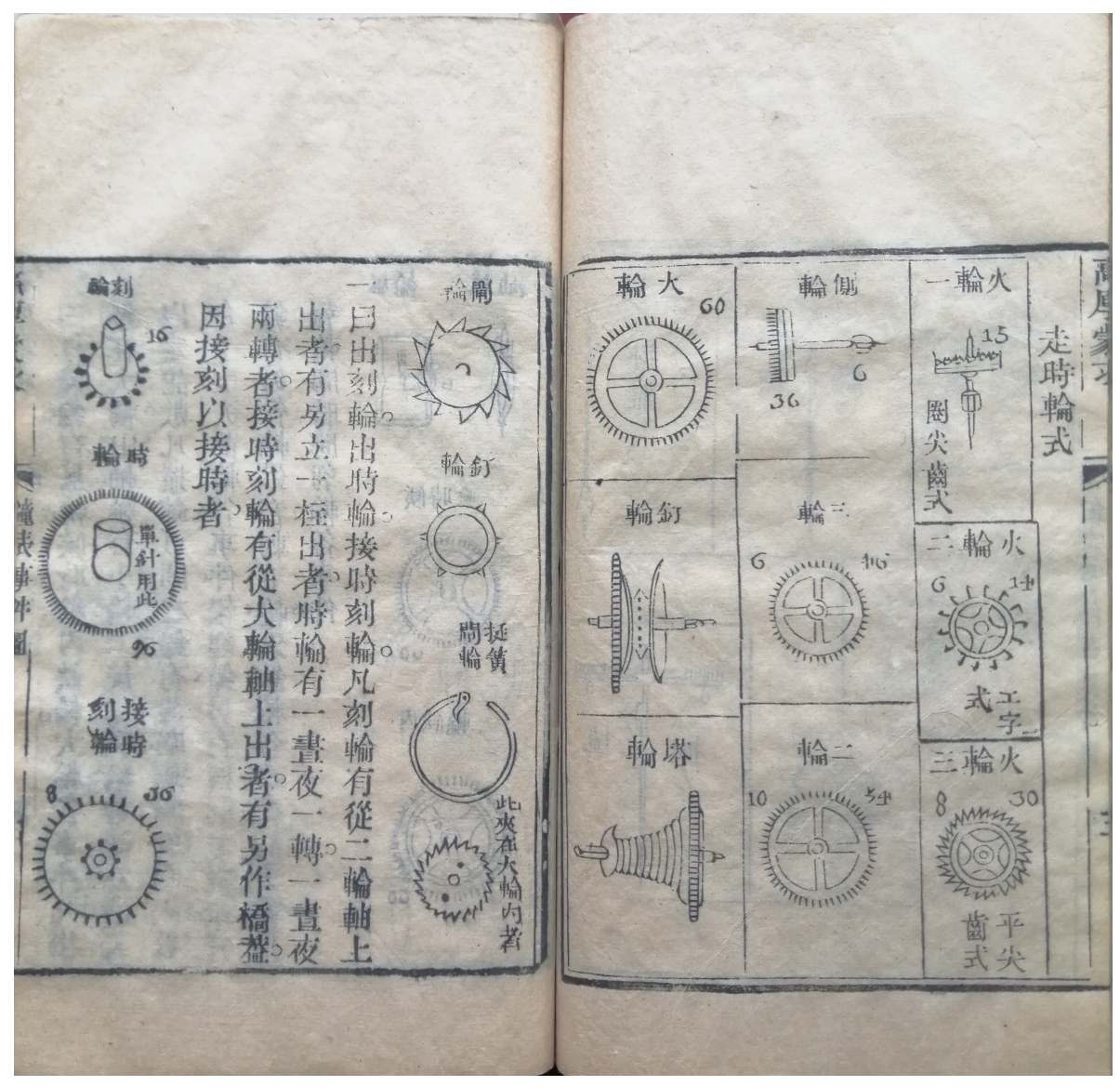

Figure 10: Xu Chaojun's book on clocks (Xu 1807, 3-4).

After the Opium War, with the significant impact of imported clocks and watches, many clock-making workshops turned to merely repairing old clocks and some were even forced to close down altogether. Only factories such as the May War Lee Clock Manufacturer, which introduced new techniques and equipment, could produce competitive varieties of clocks. The products of this factory once won a gold medal at the Panamanian Clock Fair in 1915. In the nineteenth and early twentieth centuries, the Chinese clock and watch industry did not have the same industrial and scientific foundation as the industries in Western countries.

\section{Conclusion}

Catholic missionaries were the initiators in the introduction of European clocks and watches into China, in the form of physical clocks and craftsmen's techniques. The Jesuits realized that their opportunities for further missions depended on good relations with the Chinese authorities. Therefore, clocks, other techniques, and scientific 
knowledge were the key for them to gain a foothold and preach their religion in China. From the perspective of Jesuit Matteo Ricci, the introduction of clocks, prisms, and the like lubricated the gears of social progress (Ricci and Trigault 1983, 377-378). That emperors and their courtiers were fond of clocks had partly driven the transmission of clocks and related technology.

European clocks obviously outperformed traditional Chinese timepieces in terms of techniques and functions at that time. Therefore, European clocks filled a gap and were more easily accepted by the Chinese (Zhang 2017). In addition, the Chinese were so familiar with the techniques adopted in European clocks, such as transmission gears, movable puppets, and metal parts, that it would not be difficult to imitate the imported clocks and develop their own clock handicraft industry. From the seventeenth to the mid-nineteenth century, although clocks had already met the daily timing needs of the rich and powerful, the timepiece used in the Astronomical Bureau (Observatory) was still the multi-tank clepsydra, which enabled precise timing.

The rise of the clock handicraft industry greatly enriched China's metal techniques, and especially boosted the advancement of cold processing techniques. This advancement was mainly manifested in the construction of complex transmission gears, winding springs, and escapements, especially the processing of parts such as metal gears and the application of tools such as the small lathe. In terms of craftsmanship, the highest position must belong to the Clock-Constructing Unit led by European craftsmen in the Qing imperial court, followed by private clock-making workshops in other places such as Guangzhou and Suzhou. Most Chinese craftsmen seldom had the chance of contact with European craftsmen, so they were restricted to imitating European clocks, with no related theoretical knowledge and limited technical innovations.

\section{Acknowledgments}

The author would like to thank Associate Professor Huang Xing 黄兴 and Associate Professor Chen $\mathrm{Pu}$ 陈朴 for their help in checking some references. His gratitude extends to Dr. Tilly Blyth, Dr. Chen Yu-Hsun 陈羽薰, Dr. Carol Chung, Professor Feng Lisheng 冯立昇, Dr. Li Yezhuo 李晔卓, Mr. Roger Smith, Ms. Emma Stirling-Middleton, and Professor Yao Yan'an 姚燕安 for relevant discussions, and to Professor Chen Shigang 陈士刚 for supplying images.

\section{References}

Aisin Gioro, Yongrong 永瑢, and Ji Yun 紀昀, eds. 1986. Yingyin Wenyuange Siku quanshu 景印文 淵閣四庫全書 [Photocopied Complete Collection in Four Treasuries], vol. 1300. Taipei: The Commercial Press. 
Bernard, H. 1936. Tianzhujiao shiliu shiji zai Hua chuanjiao zhi 天主教十六世紀在華傳教誌 [Aux Portes de la Chine les missionaries du XVI Siècle], translated by Xiao Junhua 蕭濬華. Shanghai: The Commercial Press.

Chen, Kaige 陈凯歌. 1981. “Qingdai Suzhou de zhongbiao zhizao” 清代苏州的钟表制造 [The Manufacture of Clocks in Suzhou, the Qing Dynasty]. Gugong Bowuyuan yuankan 故宫博物院院 刊 [Palace Museum Journal] (4): 90-94.

Chen, Zuwei 陈祖维. 1984. “Ouzhou jixie zhongbiao de chuanru he Zhongguo jindai zhongbiao ye de fazhan” 欧洲机械钟表的传入和中国近代钟表业的发展 [The Introduction of European Mechanical Clocks and the Development of the Modern Chinese Clock-Making Industry]. Zhongguo keji shiliao 中国科技史料 [China Historical Materials of Science and Technology] (1): 94-98.

Fang, Hao 方豪. 1987. Zhong Xi Jiaotong Shi 中西交通史 [The History of Communication between China and the West]. Changsha: Yuelu Press.

Ju, Deyuan 鞠德源. 1989. “Qingdai Yesuhuishi yu Xiyang qiqi” 清代耶稣会士与西洋奇器 [The Jesuits and Western Wonderful Machines in the Qing Dynasty]. Gugong Bowuyuan yuankan (12): 13-23, 83.

Liu，Yuefang 刘月芳. 1989. “Qinggong zuozhong chu” 清宫做钟处 [The Clock-Constructing Unit in Qing China]. Gugong Bowuyuan yuankan (4): 49-54.

Needham, Joseph. 1965. Mechanical Engineering. Vol. 4, part 2 of Science and Civilisation in China. Cambridge: Cambridge University Press.

Ricci, Matteo, and Nicolas Trigault. 1983. Li Madou Zhongguo zhaji 利玛窦中国札记 [Regni Chinensis Descriptio], translated by He Gaoji 何高济 et al. Beijing: Zhonghua Book Company.

Shang, Zhinan 商芝楠. 1986. “Qingdai gongzhong de Guangdong zhongbiao” 清代宫中的广东钟 表 [The Clocks Made in Guangdong Used in the Palace of the Qing Dynasty]. Gugong Bowuyuan yuankan (3): 10-12.

$\mathrm{Su}$, Song 蘇頌. 1994. Xin yixiang fayao 新儀像法要 [Essentials of Method of Constructing the New Armillary Sphere and Celestial Globe], chap. 3, 4. In vol. 1 of Jishu juan 技術卷 [Technology], edited by Hua Jueming 華覺明. Zhongguo kexue jishu dianji tonghui 中國科學技術 典籍通彙 [Compendium of Sources on Chinese Science and Technology]. Zhengzhou: Elephant Press.

Wang, Zhenduo 王振鐸. 1958. “Jiekai le woguo 'tianwenzhong' de mimi: Songdai shuiyun yixiangtai fuyuan gongzuo jieshao” 揭开了我国 “天文鐘” 的秘密一一宋代水运仪象台复原工 作介紹 [Unveiling the Secret of Chinese Astronomical Clockwork: Introduction to the Restoration of the Song Astronomical Clock-Tower]. Wenwu cankao ziliao 文物参考资料 [Cultural Relics Reference Materials] (9): 1-9.

Wang, Zheng 王徵. 1830. Xinzhi zhuqi tushuo 新制諸器圖說 [Illustrations and Descriptions of the New-Built Devices]. Chengdu: Lailutang 來鹿堂 edition.

Xu, Chaojun 徐朝俊. 1807. Ziming zhongbiao tushuo 自鳴鐘錶圖說 [Illustrations and Descriptions of Self-Sounding Clocks and Watches]. Volume 3 of Gao hou meng qiu 高厚蒙求. Songjiang: Yunjian Xushi edition.

Zhang, Baichun 张柏春. 2017. “Transmission, Cooperation and Competition in Device Construction between China and Europe in 16th-18th Centuries." Nova Acta Leopoldina (414): 
99-111.

Zhang, Baichun, Tian Miao 田永, Matthias Schemmel, Jürgen Renn, and Peter Damerow. 2008. Chuanbo yu huitong: Qiqi tushuo yanjiu yu jiaozhu 传播与会通一一奇器图说研究与校注 [Transmission and Integration: Illustrations and Descriptions of Extraordinary Devices: New Research and Annotated Edition]. Nanjing: Phoenix Science Press.

Zhang, Li 张力, and Liu Jiantang 刘鉴唐. 1987. Zhongguo jiaoan shi 中国教案史 [The History of Religious Cases in China]. Chengdu: Sichuan Academy of Social Sciences Press. 